\title{
Upaya Peningkatan Status Kesehatan Pada Ibu Hamil Melalui Deteksi Dini Pre Eklamsi (Program Penyuluhan Rawat Jalan) Di Puskesmas Mojosari Kecamatan Mojosari Kabupaten Mojokerto
}

\author{
Dhonna Anggreni ${ }^{1}$, Ika Yuni Susanti, Dyah Siwi Hety ${ }^{3}$ \\ ${ }^{1,2}$ Prodi D3 Kebidanan Stikes Majapahit \\ Email korespondensi : dhonnaanggreni@gmail.com
}

\begin{abstract}
Abstrak
Angka Kematian Ibu (AKI) di Indonesia masih belum mencapai target MDGs yaitu 102 per 100.000 kelahiran hidup. Di provinsi Jawa Timur AKI juga masih terbilang tinggi. Pada tahun 2017, Kabupaten Mojokerto mempunyai AKI tertinggi di Propinsi Jawa Timur yaitu sebanyak 29 orang. Pre eklamsi merupakan salah satu dari tiga besar penyebab kematian pada ibu. Untuk mendukung upaya penurunan AKI dan pencegahan pre eklamsi pada ibu, telah dilaksanakan kegiatan pelayanan kesehatan ibu hamil diberbagai tingkat layanan kesehatan. Tujuan dari kegiatan pengabdian masyarakat ini adalah memberikan pengalaman serta meningkatkan pengetahuan ibu hamil tentang pre eklamsi, merubah sikap dan perilaku ibu hamil sehingga bisa mencegah terjadinya pre eklamsi selama kehamilan serta terbentuknya Program Penyuluhan Rawat Jalan (Penyuraja) tentang pre eklamsi. Kegiatan ini dilakukan di Puskesmas Mojosari Kecamatan Mojosari Kabupaten Mojokerto. Sasaran dari kegiatan ini adalah ibu-ibu hamil yang memeriksakan kehamilan ke Puskesmas Mojosari. Kegiatan ini dilakukan dengan metode pemberian penyuluhan serta pemberian leaflet pada ibu. Hasil dari kegiatan ini adalah meningkatnya pengetahuan ibu hamil mengenai pre eklamsi serta sudah terbentuknya Program Penyuluhan Rawat Jalan (Penyuraja) tentang preeklamsi. Ibu hamil harus selalu menjaga kesehatannya dan selalu mengikuti arahan tenaga kesehatan agar bisa mencegah pre eklamsi selama kehamilan.
\end{abstract}

Kata kunci : pencegahan pre eklamsi, Program Penyuluhan Rawat Jalan

\begin{abstract}
The Maternal Mortality Rate (MMR) in Indonesia has not yet reached the MDGs target of 102 per 100,000 live births. In East Java province, MMR is still relatively high. In 2017, Mojokerto Regency had the highest MMR in East Java Province, which was 29 people. Pre-eclampsia is one of the top three causes of death in mothers. To support efforts to reduce MMR and prevent pre-eclampsia in mothers, health service activities for pregnant women have been carried out at various levels of health services. The purpose of this community service activity is to provide experience and increase knowledge of pregnant women about pre-eclampsia, change the attitudes and behavior of pregnant women so that they can prevent pre-eclampsia during pregnancy and the formation of an Outpatient Counseling Program (Penyuraja) about pre-eclampsia. This activity was carried out at the Mojosari Puskesmas, Mojosari District, Mojokerto Regency. The target of this activity is pregnant women who have pregnancy checks at the Mojosari Health Center. This activity is carried out by providing counseling methods and giving leaflets to mothers. The result of this activity is an increase in the knowledge of pregnant women about pre-eclampsia and the establishment of an outpatient counseling program on pre-eclampsia. Pregnant women must always maintain their health and always follow the directions of health workers in order to prevent pre-eclampsia during pregnancy.
\end{abstract}

Key words: prevention of pre-eclampsia, outpatient counseling program 


\section{PENDAHULUAN}

Angka Kematian Ibu (AKI) merupakan salah satu indikator untuk melihat keberhasilan kesehatan ibu pada suatu negara. Tantangan bagi bangsa Indonesia adalah masih tingginya Angka Kematian Ibu (AKI), dibanding negara-negara yang lain. Angka Kematian Ibu di Indonesia berdasaran data periode1991-2015 telah terjadi penurunan dari 390 menjadi 305 per 100.000 kelahiran hidup, namun angka tersebut masih belum mencapai target MDGs yaitu 102 per 100.000 kelahiran hidup (Kementrian Kesehatan Republik Indonesia, 2019).

Pada provinsi Jawa Timur (Jatim), Angka kematian ibu (AKI) cenderung meningkat. Menurut Supas tahun 2016 target AKI sebesar 305 per 100.000 kelahiran hidup. Namun terjadi peningkatan di tahun 2017 target mencapai 91,92 per 100.000 kelahiran hidup. Angka ini mengalami peningkai 91 per 100.000 kelahiran hidup (Dinas Kesehatan Provinsi Jawa Timur, 2018)

Pada tahun 2017, Kabupaten Mojokerto mempunyai Angka Kematian Ibu (AKI) tertinggi di Propinsi Jawa Timur. Yaitu sebanyak 29 orang. Dan pada tahun 2018, capaian AKI ditargetkan 167/ 100.000 KH (28 ibu), namun capainnya adalah sebesar 113,1 (19 orang) (Dinas Kesehatan Kab. Mojokerto, 2019).

Berdasarkan data Laporan Kematian Ibu Kabupaten/ Kota Dinas Kesehatan Provins Jawa Timur, di dapat bahwa tiga penyebab tertinggi kematian ibu pada tahun 2017 adalah penyebab lain-lain yang berupa penyakit lain yang menyertai kehamilan, kemudian pre eklamsi/eklamsi dan terakhir adalah perdarahan. Penyebab lain-lain yaitu sebesar 29,11\% atau 154 orang, pre eklamsi/eklamsi sebesar 28,92\% atau sebanyak 153 orang dan perdarahan yaitu 26,28 \% atau sebanyak 139 orang. Penyebab AKI paling kecil adalah infeksi sebesar 3,59 \% atau sebanyak 19 orang (Dinas Kesehatan Provinsi Jawa Timur, 2018).

Upaya percepatan penurunan AKI dapat dilakukan dengan menjamin agar setiap ibu mampu mengakses pelayanan kesehatan yang berkualitas, seperti pelayanan kesehatan pada ibu hamil, pertolongan persalinan oleh tenaga kesehatan terlatih di faslitas pelayanan kesehatan, perawatan pasca persalinan bagi ibu dan bayi, perawatan khusus dan rujukan jika terjadi komplikasi, termasuk pelayanan KB pasca salin (Kementrian Kesehatan Republik Indonesia, 2019).

Untuk mendukung upaya penurunan AKI tersebut, telah dilaksanakan kegiatan pelayanan kesehatan ibu di berbagai tingkatan pelayanan kesehatan baik di tingkat masyarakat Puskesmas serta Rumah Sakit. Kegiatan tersebut melibatkan lintas program dan lintas sektor 
terkait serta jejaring lain yang turut mendukung upaya tersebut. Salah satu upaya yang diharapkan dapat mendukung upaya tersebut, adalah dengan melaksanakan program penyuluhan tentang resiko tinggi pada masa kehamilan. Program ini diharapkan meningkatkan kualitas kesehatan bagi ibu dan bayi.

Program penyuluhan rawat jalan (Penyuraja) merupakan salah satu program rawat jalan yang bekerja sama dengan bagian promosi kesehatan puskesmas yang bertujuan untuk meningkatkan derajat kesehatan ibu dan anak. Kegiatan penyuluhan rawat jalan (Penyura) ini bertujuan untuk memberikan pengalaman dan pengetahuan kepada ibu hamil tentang pre eklamsi. Mulai dari pengertian, tujuan, manfaat dan jadwal kunjungannya, serta cara pencegahan pre eklamsi. Selain meningkatkan pengetahuan ibu, kegiatan ini juga bertujuan agar timbulnya interaksi antar ibu hamil sehingga mereka dapat bertukar pikiran dan pengalaman seputar peningkatan status kesehatan.

\section{MASALAH}

Permasalahan yang ada di wilayah kerja Puskesmas Mojosari adalah :

1) Masih tingginya angka kejadian pre eklamsi di wilayah kerja Puskesmas Mojosari, yaitu pada tahun 2018 sebesar 38 kasus, sedangkan mulai Januari - Juli 2019 sekitar 29 kasus.

2) Kurangnya pengetahuan ibu hamil mengenai pre eklamsi dan cara pencegahannya

\section{METODE}

Kegiatan Pengabdian Masyarat ini dilaksanakan di Puskesmas Mojosari Kabupaten Mojokerto. Kegiatan ini dilaksanakan dari tanggal 1 September sampai dengan 30 November 2019. Sasaran kegiatan ini adalah seluruh ibu hamil yang memeriksakan kehamilan Puskesmas Mojosari. Adapun tahapan pelaksanaan kegiatan ini adalah

1) Survei Lapangan.

Survei lapangan bertujuan untuk mengamati situasi wilayah Puskesmas, yang direncanakan sebagai objek sasaran.

2) Menentukan Sasaran

Sasaran program ini yaitu ibu hamil di Wilayah Puskesmas Mojosari Kecamatan Mojosari Kabupaten Mojokerto.

3) Koordinasi 
Berkoordinasi dengan pihak Puskesmas Mojosari, untuk menentukan kesepakatan mufakat antara pelaksana program dengan masyarakat.

\section{4) Sosialisasi Program}

Sosialisasi program bertujuan untuk memberikan informasi mengenai rencana serangkaian pelaksanaan program yang disampaikan kepada kader, bidan, seluruh wilayah Puskesmas Mojosari.

\section{5) Pelaksanaan Program}

Pertemuan penyuluhan rawat jalan ini dilakukan 4-5 kali pertemuan pada ibu hamil. Pada setiap pertemuan akan dilakukan pre test dan setelah itu dilakukan pemberian materi tentang pre eklamsi. Setelah pemberian materi di lanjutkan evaluasi. Evaluasi dilakukan untuk melihat kesesuaian dengan hasil kesepakatan fasilitator dengan peserta. Pada setiap pertemuan, materi yang akan disampaikan adalah tentang pengertian, tanda gejala, dan komplikasi pre eklamsi serta cara pencegahan pre eklamsi. Diakhir perteymuan dilakukan tanya jawab tentang materi yang telah diberikan. Diharapkan materi yang diberikan dapat dipelajari, dipahami dan diterapkan di rumah. Waktu pertemuan disesuaikan dengan jadwal kunjungan hamil di Puskesmas Mojosari, yaitu setiap hari selasa dan rabu.

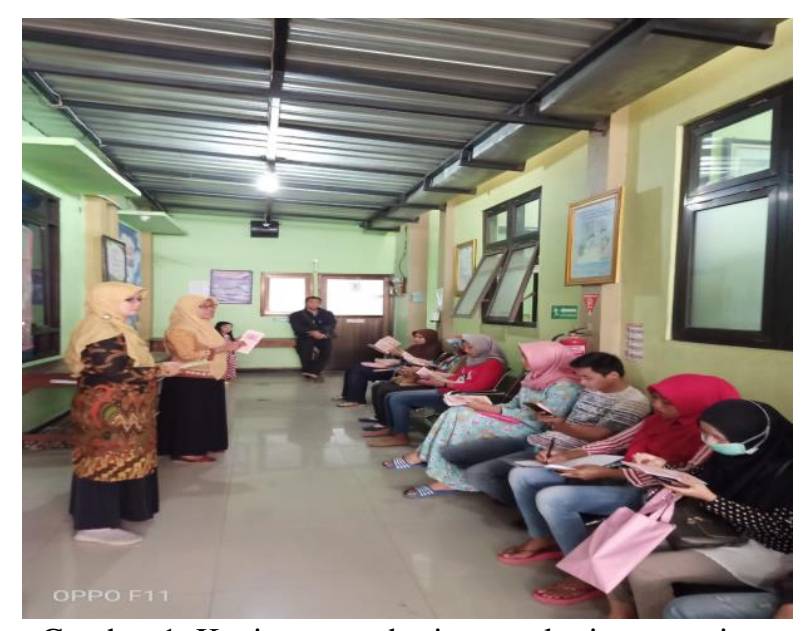

Gambar 1. Kegiatan pemberian pemberian materi

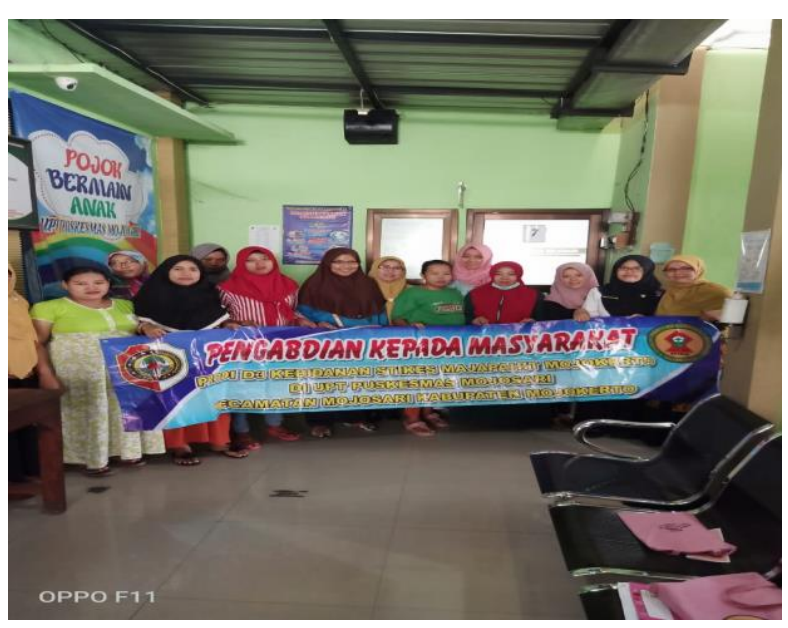

Gambar 2. Kegiatan pemberian pemberian materi

\section{HASIL DAN PEMBAHASAN}

\section{1) Hasil}

Kegiatan pengabdian masyarakat ini dilakukan sebanyak lima kali sesuai dengan jadwal kunjungan hamil di Puskesmas Mojosari. Semua sasaran kegiatan akan mengisi kuesioner sebelum dan sesudah kegiatan. Adapun hasil dari kegiatan ini adalah 
Tabel 1. Tabel usia ibu hamil

\begin{tabular}{|c|c|c|}
\hline Usia ibu hamil & Frekuensi & Presentase \\
\hline $0-20$ tahun & 27 & 21,3 \\
\hline $21-35$ tahun & 75 & 59 \\
\hline$>35$ tahun & 25 & 19,7 \\
\hline Jumlah & 127 & 100 \\
\hline
\end{tabular}

Tabel 1 menunjukkan menunjukkan bahwa sebagian besar ibu hamil berusia 21-35 tahun $(59 \%)$.

Tabel 2. Tabel pengetahuan ibu hamil sebelum dan sesudah di berikannya materi penyuluhan rawat jalan (Penyuraja) tentang pre eklamsi

\begin{tabular}{lcccc}
\hline \multirow{2}{*}{ Pengetahuan } & \multicolumn{3}{c}{ Sebelum } & \multicolumn{2}{c}{ Sesudah } \\
\cline { 2 - 5 } & $\mathrm{F}$ & $\%$ & $\mathrm{~F}$ & $\%$ \\
\cline { 2 - 5 } Baik & 57 & 44,9 & 95 & 74,8 \\
Cukup & 49 & 38,6 & 28 & 22 \\
Kurang & 21 & 16,5 & 4 & 3,2 \\
\hline Jumlah & 127 & 100 & 127 & 100 \\
\hline
\end{tabular}

Tabel 2 menunjukkan hasil bahwa terjadi peningkatan pengetahuan ibu sebelum dan sesudah kegiatan. Sebelum dilakukan kegiatan, tingkat pengetahuan ibu hamil dengan kategori kurang sebesar 16,5\%. Setelah dilakukan kegiatan, jumlah ibu hamil dengan tingkat pengetahuan kurang menurun menjadi $3,2 \%$.

\section{2) Pembahasan}

Hasil kegiatan menunjukkan bahwa sebagian besar ibu hamil berusia 21-35 tahun (59\%). Untuk tingkat pengetahuan ibu hamil, terjadi peningkatan pengetahuan ibu sebelum dilakukan kegiatan Penyuraja dengan sesudah dilakukan kegiatan Penyuraja. Sebelum dilakukan kegiatan Penyuraja, tingkat pengetahuan ibu hamil dengan kategori kurang sebesar 16,5\%. Setelah dilakukan kegiatan Penyuraja, jumlah ibu dengan tingkat pengetahuan kurang menurun menjadi 3,2\%. Hasil pengukuran ini menjunjukkan bahwa terjadinya peningkatan pengetahuan ibu hamil selama di kegiatan penyuluhan.

Preeklamsia merupakan salah satu penyulit kehamilan yang ditandai dengan peningkatan tekanan darah berkisar 140/90 $\mathrm{mmHg}$, proteinuria dan edema. Preeklamsia biasanya terjadi pada ibu hamil trimester ketiga. Preeklamsia berbahaya bagi ibu dan janin seperti terjadinya gangguan pertumbuhan janin, bayi lahir lebih kecil dan ibu bisa terjadi perdarahan hingga syok hipovolemik. Untuk pencegahan preeklamsia selama kehamilan dapat dilakukan dengan pemantauan tekanan darah pada ibu hamil secara teratur (Bobak, 2005).

Penyuluhan yaitu suatu kegiatan atau usaha untuk menyampaikan pesan kesehatan kepada 
masyarakat, kelompok atau individu. Dengan harapan bahwa dengan adanya pesan tersebut individu dapat memperoleh pengetahuan tentang kesehatan yang lebih baik. Akhirnya pengetahuan tersebut diharapkan dapat berpengaruh terhadap perilakunya (Notoatmodjo. S., 2012).

Penyuluhan pada ibu hamil sangat diperlukan agar pengetahuan ibu bertambah sehingga ibu mau memeriksakan kehamilan nya secara teratur dan mampu mencegah terjadinya pre eklamsi selama kehamilan dengan mengikuti arahan yang diberikan oleh tenaga kesehatan. Selain itu, penyuluhan juga dapat memotivasi ibu untuk selalu menjaga kesehatannya dan selalu memeriksakan kehamilannya ke tenaga kesehatan.

\section{KESIMPULAN}

Kesimpulan yang didapat dari kegiatan pengabdian masyarakat yang dilakukan di Puskesmas Mojosari adalah sebagi berikut:

1) Adanya peningkatan pengetahuan ibu hamil tentang pre eklamsi pada ibu hamil.

2) Terbentuknya terbentuknya Program Penyuluhan Rawat Jalan (Penyuraja) tentang preeklamsi

\section{DAFTAR PUSTAKA}

Bobak, L. (2005). Keperawatan Maternitas. EGC.

Dinas Kesehatan Kab. Mojokerto. (2019). Laporan Kinerja Tahun 2018 Dinas Kesehatan Kab. Mojokerto. Dinas Kesehatan Kab. Mojokerto.

Dinas Kesehatan Provinsi Jawa Timur. (2018). Profil Kesehatan Provinsi Jawa Timur Tahun 2017. Dinas Kesehatan Provinsi Jawa Timur.

Kementrian Kesehatan Republik Indonesia. (2019). Profil Kesehatan Indonesia 2018. Kementrian Kesehatan Republik Indonesia.

Notoatmodjo. S. (2012). Promosi Kesehatan dan Perilaku Kesehatan. Rineka Cipta. 